\title{
Quantitative Trait Loci Mapping for Dairy Cattle Production Traits Using a Maximum Likelihood Method
}

\author{
Y. Liu, ${ }^{1}$ G. B. Jansen, ${ }^{1}$ and C. Y. Lin ${ }^{1,2}$ \\ ${ }^{1}$ CGIL, Dept. of Animal \& Poultry Science, University of Guelph, \\ Ontario, Canada N1G 2W1 \\ ${ }^{2}$ Dairy and Swine Research and Development Centre, \\ Contribution \#754, Agriculture and Agri-Food Canada, \\ Lennoxville, Quebec J1M 1 Z3
}

\section{ABSTRACT}

A maximum likelihood method was developed for QTL mapping in half-sib designs and compared to the regression method in analyses of both field and simulated data. The field data consisted of milk production evaluations of 433 progeny tested sons of 6 sires and 64 microsatellite markers distributed over 12 chromosomes. Based on permutation tests, 5 significant QTL were detected in the field data by the regression method compared with 10 by the maximum likelihood method $(P<0.05)$. In field data analysis, the maximum likelihood method detected more significant QTL and had a smaller residual variance than the regression method. The simulation included 9 scenarios differing in number of families, family size, QTL variance, and marker density, each replicated 100 times. The simulation results suggested that, as for the regression method, the precision of estimating QTL from the maximum likelihood method improves with increasing number of sons per sire, increasing the ratio of QTL to phenotypic variance, and decreasing marker interval. The maximum likelihood method had a smaller dispersion of estimated QTL positions than the regression method in 6 of 9 scenarios simulated. Overall, the maximum likelihood method shows potential advantage in QTL detection over the regression method, especially in the situations with less favorable conditions for QTL detection.

(Key words: QTL mapping, dairy production trait, mixture model, maximum likelihood)

Abbreviation key: DYD = daughter yield deviation; $\mathbf{E M}=$ expectation-maximization, LOD = logarithm of odds, $\mathbf{M L}=$ maximum likelihood.

\section{INTRODUCTION}

The production traits of dairy cattle, such as milk, fat, and protein yields as well as fat and protein percent-

Received June 4, 2002.

Accepted June 8, 2003.

Corresponding author: Y. Liu; e-mail: yuefu@ccsi.ca. ages are thought to follow quantitative inheritance, influenced by numerous polygenes. Genetic research on these traits has generally focused on the aggregate effect of the polygenes. The effects of individual genes underlying the traits have rarely been studied before the advent of molecular markers. Molecular markers provide a possible way to study the underlying loci affecting quantitative traits and infer their locations and effects.

Numerous studies on QTL mapping of milk production traits of dairy cattle have been reported. The regression method of interval mapping (Knott et al., 1996) is a common statistical method used to locate QTL for dairy production traits (Spelman et al., 1996; Zhang et al., 1998; Velmala et al., 1999; Heyen et al., 1999; Nadesalingam et al., 2001; Plante et al., 2001; Ron et al., 2001; Freyer et al., 2002). The REML method (Grignola et al., 1996a, 1996b) was used by Zhang et al. (1998) and Freyer et al. (2002) to map QTL of dairy production traits for US and German Holstein populations. Georges et al. (1995) developed a maximum likelihood (ML) method for single-family analysis to map QTL of dairy production traits from the US Holstein data.

Simulation studies (Xu, 1995; Kao, 2000) have shown that ML methods yield smaller residual variances and larger likelihood ratio statistics than the regression method in QTL mapping of inbred lines. In plants and laboratory animals, ML methods based on the mixture model and the expectation-maximization (EM) algorithm (Lander and Botstein, 1989; Zeng, 1994; Liu and Zeng, 2000) have been widely used in QTL mapping. These procedures for estimating QTL effects and positions are well formulated. In contrast, the ML method has seldom been used for QTL mapping in livestock populations such as dairy cattle. This study aims to simplify the ML method and formulates the equations analogous to conventional linear model equations to facilitate its application. A FORTRAN program (available on request) was developed to analyze both field data of dairy cattle and simulated data in this study. 
Table 1. Conditional probabilities of QTL alleles given the gametic types of flanking markers. ${ }^{1}$

\begin{tabular}{llll}
\hline Marker $(M)$ & $\operatorname{Pr}(M)$ & $p_{i j}=\operatorname{Pr}\left(Q_{1} \mid M\right)$ & $1-p_{i j}=\operatorname{Pr}\left(Q_{2} \mid M\right)$ \\
\hline $\mathrm{M}_{1} \mathrm{~N}_{1}$ & $(1-r) / 2$ & $\left(1-r_{1}\right)\left(1-r_{2}\right) /(1-r)$ & $r_{1} r_{2} /(1-r)$ \\
$\mathrm{M}_{1} \mathrm{~N}_{2}$ & $r / 2$ & $\left(1-r_{1}\right) r_{2} / r$ & $r_{1}\left(1-r_{2}\right) / r$ \\
$\mathrm{M}_{2} \mathrm{~N}_{1}$ & $r / 2$ & $r_{1}\left(1-r_{2}\right) / r$ & $\left(1-r_{1}\right) r_{2} / r$ \\
$\mathrm{M}_{2} \mathrm{~N}_{2}$ & $(1-r) / 2$ & $r_{1} r_{2} /(1-r)$ & $\left(1-r_{1}\right)\left(1-r_{2}\right) /(1-r)$ \\
\hline
\end{tabular}

\footnotetext{
${ }^{1}$ The recombination rates of a QTL with flanking markers 1 and 2 are $r_{1}$ and $r_{2}$, respectively, and $r$ is
} the recombination rate between the two flanking markers.

\section{MATERIALS AND METHODS}

\section{Maximum Likelihood Method}

To detect QTL, phenotypic observations need to be described in terms of QTL effects. In a half-sib design, an observation, $y_{i j}$ of $\operatorname{son} j\left(j=1,2, \ldots, n_{i}\right)$ of sire $i(i=$ $1,2, \ldots, k)$ can be expressed as,

$$
y_{i j}=\boldsymbol{x}_{i j}{ }^{\prime} \boldsymbol{\beta}+\xi_{i j} \boldsymbol{z}_{i j}{ }^{\prime} \boldsymbol{a}+e_{i j},
$$

where $\beta$ is a column vector of fixed effects and may include an overall mean, half-sib family means, etc; $\boldsymbol{x}_{i j}{ }^{\prime}$ is the row of design matrix $\boldsymbol{X}$ corresponding to $y_{i j} ; \mathbf{a}=$ $\left(a_{1}, a_{2}, \ldots, a_{k}\right)^{\prime}$ is a column vector of QTL effects, in which $a_{i}$ is the fixed substitution effect between the two QTL alleles within sire $i ; \boldsymbol{z}_{i j}{ }^{\prime}$ is the row of design matrix $\boldsymbol{Z}$ corresponding to $y_{i j} ; \xi_{i j}$ is an indicator variable equal to 1 if son $i j$ inherits $Q_{i}^{1}$ from sire $i$ and equal to 0 if son $i j$ inherits $Q_{i}^{2}$ from sire $i$; and $e_{i j}$ is residual error with $e_{i j} \sim N\left(0, \sigma_{i j}^{2}\right)$ or $\boldsymbol{e} \sim N\left(\boldsymbol{0}, \boldsymbol{R} \sigma^{2}\right)$. For dairy cattle, $y_{i j}$ can be an EBV or daughter yield deviation (DYD) with reliability $r_{i j}$. The residual variance, $\sigma_{i j}^{2}$, is taken as $\sigma^{2} /$ $r_{i j}$ and $\boldsymbol{R}=\operatorname{diag}\left\{1 / r_{i j}\right\}_{N \times N}$, where $N=\sum_{i=1}^{k} n_{i}$. When $y_{i j}$ is EBV, approximate $r_{i j}$ is routinely available along with EBV results. For DYD, $r_{i j}$ is taken as $\left[1+0.25\left(m_{i j}-\right.\right.$ 1) $\left.h^{2}\right] / m_{i j}$ (Spielman et al., 1996), where $m_{i j}$ is the number of daughters used to calculate DYD for son $i j$. The sires are assumed to be unrelated and mated randomly with dams (Knott et al., 1996).

Given phenotypic observations and marker data, the likelihood of the parameters $\left(\boldsymbol{\beta}, \boldsymbol{a}\right.$, and $\left.\sigma^{2}\right)$ is

$$
\begin{gathered}
L\left(\boldsymbol{\beta}, \boldsymbol{a}, \sigma^{2} \mid \boldsymbol{y}, M\right) \\
=\prod_{i=1 j=1}^{k} \prod_{\mathrm{i}}^{n_{\mathrm{i}}}\left(2 \pi \sigma_{i j}^{2}\right)^{-1 / 2}\left\{p_{i j} \exp \left[-\frac{1}{2 \sigma_{i j}^{2}}\left(y_{i j}-\boldsymbol{x}_{i j}^{\prime} \boldsymbol{\beta}-a_{i}\right)^{2}\right]\right. \\
\left.\quad+\left(1-p_{i j}\right) \exp \left[-\frac{1}{2 \sigma_{i j}^{2}}\left(y_{i j}-\boldsymbol{x}_{i j}^{\prime} \boldsymbol{\beta}\right)^{2}\right]\right\},
\end{gathered}
$$

where $p_{i j}$ is the conditional probability that son $i j$ inherits the first QTL allele of sire $i$, inferred from the marker information. The conditional probability that a son inherits one of the sire's QTL allele is calculated as in Table 1. For every QTL position tested, $p_{i j}$ is calculated using the closest pair of informative markers for the $j$ th son of the $i$ th sire, as in Knott et al. (1996). When the outermost markers were uninformative, $p_{i j}$ was computed from the nearest single markers. Haldane's mapping function is used to convert genetic distance to recombination frequency.

Because QTL genotypes (independent variables) are not observable, standard programs for linear models cannot be used. To find the ML estimates of QTL parameters, a convenient way is to use the techniques for missing data analysis as Lander and Botstein (1989) suggested, taking QTL genotypes as missing data. Specifically, the EM algorithm for finite mixtures described by Dempster et al. (1977) was used. The conditional expectation of the log-likelihood for the complete data with respect to missing data (Little and Rubin, 1987; Meng and Rubin, 1993) in the current application of the EM algorithm is

$$
\begin{gathered}
Q\left(\theta \mid \theta^{[t]}\right)=\sum_{i=1 j=1}^{k} \sum_{\mathrm{i}}^{n_{\mathrm{i}}}\left\{\log \left[\phi\left(y_{i j} \mid \boldsymbol{\beta}, \boldsymbol{a}, \sigma^{2}\right) p_{i j}\right] \pi_{i j}^{[t]}\right. \\
\left.+\log \left[\phi\left(y_{i j} \mid \boldsymbol{\beta}, \sigma^{2}\right)\left(1-p_{i j}\right)\right]\left(1-\pi_{i j}{ }^{[t]}\right)\right\}
\end{gathered}
$$

where

$$
=\frac{\pi_{i j}^{[t]}}{p_{i j} \phi\left(y_{i j} \mid \boldsymbol{\beta}^{[t]}, \boldsymbol{a}^{[t]}, \sigma^{2[t]}\right)+\left(1-p_{i j}\right) \phi\left(y_{i j} \mid \boldsymbol{\beta}^{[t]}, \sigma^{2[t]}\right)}
$$

Maximizing $Q\left(\theta \mid \theta^{[t]}\right)$ by differentiation leads to the following equations for parameter estimation:

$$
\begin{gathered}
\left(\begin{array}{c}
\boldsymbol{X}^{\prime} \boldsymbol{R}^{-1} \boldsymbol{X} \boldsymbol{X}^{\prime} \boldsymbol{R}^{-1} \boldsymbol{U} \\
\boldsymbol{U}^{\prime} \boldsymbol{R}^{-1} \boldsymbol{X} \boldsymbol{Z}^{\prime} \boldsymbol{R}^{-1} \boldsymbol{U}
\end{array}\right)^{[t]}\left(\begin{array}{c}
\boldsymbol{\beta}^{[t+1} \\
\boldsymbol{a}^{[t+1]}
\end{array}\right)=\left(\begin{array}{l}
\boldsymbol{X}^{\prime} \boldsymbol{R}^{-1} \boldsymbol{y} \\
\boldsymbol{U}^{\prime} \boldsymbol{R}^{-1} \boldsymbol{y}
\end{array}\right)^{[t]} \\
\sigma^{2[t+1]}=\frac{1}{N}\left[\left(\boldsymbol{y}-\boldsymbol{X} \boldsymbol{\beta}^{[t+1]}\right)^{\prime} \boldsymbol{R}^{-1}\left(\boldsymbol{y}-\boldsymbol{X} \boldsymbol{\beta}^{[t+1]}\right)\right. \\
+\boldsymbol{a}^{[t+1]} \boldsymbol{Z}^{\prime} \boldsymbol{R}^{-1} \boldsymbol{U}^{[t]} \boldsymbol{a}^{[t+1]}-2\left(\boldsymbol{y}-\boldsymbol{X} \boldsymbol{\beta}^{[t+1]}\right)^{\prime} \boldsymbol{R}^{-1} \boldsymbol{U}^{[t]} \boldsymbol{a}^{[t+1]}
\end{gathered}
$$

where $\boldsymbol{U}^{[t]}=\left\{\pi_{i j}{ }^{[t]} \boldsymbol{z}_{i j}{ }^{\prime}\right\}_{N \times k}$.

Matrix $\boldsymbol{U}$ is equal to matrix $\boldsymbol{Z}$ with the element of 1 in $\boldsymbol{z}_{i j}{ }^{\prime}$ replaced by $\pi_{i j}$. The posterior probability $\pi_{i j}$ is 
calculated in the E-step, whereas the parameters $\boldsymbol{\beta}, \boldsymbol{a}$, and $\sigma^{2}$ are estimated in the M-step by equations (5) and (6).

The logarithm of odds (LOD) score statistic is used to test the QTL effect under the null hypothesis $\left(\mathrm{H}_{0}\right)$ that $a_{\mathrm{i}}=0$ for $i=1,2, \ldots, k$, which means there is no QTL segregating at the testing position. The alternative hypothesis is that at least one of the sires' QTL effects is significant, suggesting that the test position may contain a QTL. The LOD score statistic can be formulated as

$$
L O D=\log L\left(\hat{\boldsymbol{\beta}}, \hat{\boldsymbol{a}}, \hat{\sigma}^{2}\right)-\log L\left(\hat{\boldsymbol{\beta}}_{0}, \hat{\sigma}_{0}^{2}\right)
$$

where $\log$ is the common logarithm and $\hat{\boldsymbol{\beta}}_{0}$ and $\hat{\sigma}_{0}^{2}$ are the ML estimates of the parameters under $\mathrm{H}_{0}$. These are the same as the estimates based on the reduced model, $y_{i j}=\boldsymbol{x}_{i j}{ }^{\prime} \boldsymbol{\beta}_{0}+e_{i j}$ without QTL effects $\boldsymbol{a}$, which is a nonmixture linear model. The ML estimates of the parameters under $\mathrm{H}_{0}$ are

$$
\hat{\boldsymbol{\beta}}_{0}=\left(\boldsymbol{X}^{\prime} \boldsymbol{R}^{-1} \boldsymbol{X}\right)^{-1} \boldsymbol{X}^{\prime} \boldsymbol{R}^{-1} \boldsymbol{y}
$$

which are identical to the generalized least square estimates, and

$$
\hat{\sigma}_{0}^{2}=\frac{1}{N}\left[\left(\boldsymbol{y}-\boldsymbol{X} \hat{\boldsymbol{\beta}}_{0}\right)^{\prime} \boldsymbol{R}^{-1}\left(\boldsymbol{y}-\boldsymbol{X} \hat{\boldsymbol{\beta}}_{0}\right) .\right.
$$

The LOD score is used to detect the presence of a QTL in the tested position. A position with a higher LOD score is more likely to contain a QTL. The permutation test can be applied to determine critical value based on the empirical distribution of the LOD scores (Churchill and Doerge, 1994).

\section{Regression Method}

To investigate the performance of the ML method, the regression method (Knott et al., 1996) was also applied in this study as a reference. The model used for within-sire regression is

$$
y_{i j}=\boldsymbol{x}_{i j}{ }^{\prime} \boldsymbol{\beta}+\boldsymbol{w}_{i j}{ }^{\prime} \boldsymbol{a}+e_{i j}
$$

where $\boldsymbol{w}_{i j}{ }^{\prime}=p_{i j} \boldsymbol{z}_{i j}{ }^{\prime}$ or $W=\left\{p_{i j} \boldsymbol{z}_{i j}{ }^{\prime}\right\}_{N \times k}$. Other variables are as defined in the model (1). The equations for regression analysis are

$$
\left(\begin{array}{l}
\boldsymbol{X}^{\prime} \boldsymbol{R}^{-1} \boldsymbol{X} \boldsymbol{X}^{\prime} \boldsymbol{R}^{-1} \boldsymbol{W} \\
\boldsymbol{W}^{\prime} \boldsymbol{R}^{-1} \boldsymbol{X} \boldsymbol{W}^{\prime} \boldsymbol{R}^{-1} \boldsymbol{W}
\end{array}\right)\left(\begin{array}{c}
\hat{\boldsymbol{\beta}} \\
\hat{\boldsymbol{a}}
\end{array}\right)=\left(\begin{array}{c}
\boldsymbol{X}^{\prime} \boldsymbol{R}^{-1} \boldsymbol{y} \\
\boldsymbol{W}^{\prime} \boldsymbol{R}^{-1} \boldsymbol{y}
\end{array}\right)
$$

The LOD scores were used to test the presence of a QTL for both regression and ML methods in this study.

\section{Analysis of Field Data}

Daughter yield deviations for milk, fat, and protein yields as well as fat and protein percentages were analyzed with interval mapping by both ML and regression methods. The data used in this study, whose subsets were analyzed separately by Nadesalingam et al. (2001) and Plante et al. (2001), included 6 Holstein sires with 71 to 74 genotyped sons each $(\mathrm{n}=433)$. There are, therefore, 6 family effects and 6 QTL allele substitution effects for both ML and regression methods. The means and standard deviations of the 5 traits are $275 \pm 408,9.8$ $\pm 15.2,9.6 \pm 11.9,3.7 \pm 0.16$ and $3.19 \pm 0.06$, respectively. Sires and sons were genotyped for 69 microsatellite markers distributed over 12 chromosomes (1, 3, 5, 6, 9, $10,13,15,17,20,23$, and 26). The markers covered $867.4 \mathrm{cM}$ of the genome with 2 to 9 markers per chromosome. The observed number of alleles at each marker ranges from 2 to 15 (Table 2). The number of informative markers for each sire was given by Plante et al. (2001). The MARC linkage map was applied. Dams were not genotyped. The genome was scanned by 1 cM intervals. The chromosome-wise single-trait critical values were determined by permutation tests based on the empirical distribution of 5000 replicates.

\section{Data Simulation}

To check the performance of the ML method developed for the granddaughter design, 9 cases were simulated with different number of sires, number of sons per sire, ratios of QTL variance to phenotypic variance, and marker intervals (Table 3 ). The sires were simulated as unrelated and were heterogeneous at all marker loci. A chromosome fragment of $100 \mathrm{cM}$ was simulated with evenly spaced markers having 10 alleles each at equal frequencies in the population. When marker interval was 20,10, and $5 \mathrm{cM}$, the number of markers was 6, 11, and 21, respectively. A single QTL was set at $34 \mathrm{cM}$ in all cases. Because sires are assumed to be unrelated, the QTL allelic substitution effect for each sire was sampled independently from a normal distribution and scaled to give: $-30,-40,60,-20$, and 30 for sires 1 to $5 ;-110,55,35,0$, and 20 for sires 6 to $10 ; 100,15,-65,-90$, and 40 for sires 11 to 15 . Each case consists of 100 replicates. The critical values ( $\alpha=$ 0.05 or 0.01 ) were determined by ranking the test statistic of 1000 replicates simulated without the putative QTL effects (i.e., under $\mathrm{H}_{0}$ ).

\section{RESULTS AND DISCUSSION}

\section{Field Data}

Chromosome-wise significance level of 5\% was applied to declare the possible existence of QTL in this 
Table 2. Linkage map used for QTL mapping adapted from Meat Animal Research Center (MARC) of US Department of Agriculture. ${ }^{1}$

\begin{tabular}{|c|c|c|c|c|c|c|c|c|c|}
\hline \multirow[b]{2}{*}{ Chr. } & \multicolumn{9}{|c|}{ Marker locus, map distances in cM (before /), and no. of alleles (after /) } \\
\hline & 1 & 2 & 3 & 4 & 5 & 6 & 7 & 8 & 9 \\
\hline 1 & $\begin{array}{l}\text { TGLA49 } \\
0 / 7\end{array}$ & $\begin{array}{l}\text { RM095 } \\
19.4 / 2\end{array}$ & $\begin{array}{l}\text { ILSTS004 } \\
30.1 / 10\end{array}$ & $\begin{array}{l}\text { BM } 4307 \\
33.3 / 6\end{array}$ & $\begin{array}{l}\text { INRA011 } \\
52.5 / 6\end{array}$ & $\begin{array}{l}\text { BM6506 } \\
67.3 / 7\end{array}$ & $\begin{array}{l}\text { BM1824 } \\
106.7 / 5\end{array}$ & $\begin{array}{l}\text { BM148 } \\
116.2 / 6\end{array}$ & \\
\hline 3 & $\begin{array}{l}\text { INRA006 } \\
0 / 2\end{array}$ & $\begin{array}{l}\text { FCGR2 } \\
15.5 / 2\end{array}$ & $\begin{array}{l}\text { INRA023 } \\
34.7 / 8\end{array}$ & $\begin{array}{l}\text { INRA003 } \\
40.0 / 8\end{array}$ & $\begin{array}{l}\text { BR4502 } \\
83.7 / 8\end{array}$ & $\begin{array}{l}\text { BM2924 } \\
97.0 / 5\end{array}$ & & & \\
\hline 5 & $\begin{array}{l}\text { BM6026 } \\
0 / 9\end{array}$ & $\begin{array}{l}\text { BP-1 } \\
12.1 / 9\end{array}$ & $\begin{array}{l}\text { BMC1009 } \\
33.9 / 5\end{array}$ & $\begin{array}{l}\text { MAF23 } \\
56.8 / 2\end{array}$ & $\begin{array}{l}\text { IGF1-1 } \\
67.3 / 4\end{array}$ & $\begin{array}{l}\text { BM1819 } \\
70.9 / 5\end{array}$ & $\begin{array}{l}\text { BM315 } \\
93.4 / 10\end{array}$ & $\begin{array}{l}\text { ETH152 } \\
111.6 / 7\end{array}$ & \\
\hline 9 & $\begin{array}{l}\text { BM } 4208 \\
0 / 9\end{array}$ & $\begin{array}{l}\text { BM6436 } \\
13.2 / 6\end{array}$ & $\begin{array}{l}\text { BMC701 } \\
27.9 / 11\end{array}$ & $\begin{array}{l}\text { ILSTS013 } \\
40.9 / 4\end{array}$ & $\begin{array}{l}\text { BM2504 } \\
59.4 / 4\end{array}$ & $\begin{array}{l}\text { BM1227 } \\
65.5 / 5\end{array}$ & $\begin{array}{l}\text { ETH225 } \\
76.5 / 7\end{array}$ & & \\
\hline 10 & $\begin{array}{l}\text { CSSM38 } \\
0 / 10\end{array}$ & $\begin{array}{l}\text { BM1237 } \\
12.6 / 7\end{array}$ & $\begin{array}{l}\text { BM6305 } \\
29.2 / 7\end{array}$ & $\begin{array}{l}\text { TGLA4 } \\
31.5 / 3\end{array}$ & $\begin{array}{l}\text { BM888 } \\
43.4 / 8\end{array}$ & $\begin{array}{l}\text { TGLA102 } \\
45.9 / 6\end{array}$ & $\begin{array}{l}\text { CSRM60 } \\
66.1 / 5\end{array}$ & $\begin{array}{l}\text { TGLA27 } \\
79.8 / 4\end{array}$ & $\begin{array}{l}\text { CSSM39 } \\
85.9 / 12\end{array}$ \\
\hline 13 & $\begin{array}{l}\text { BMC1222 } \\
0 / 15\end{array}$ & $\begin{array}{l}\text { BMS1145 } \\
15.7 / 8\end{array}$ & $\begin{array}{l}\text { BL42 } \\
39.4 / 2\end{array}$ & & & & & & \\
\hline 20 & $\begin{array}{l}\text { BM3517 } \\
0 / 10\end{array}$ & $\begin{array}{l}\text { BM1225 } \\
8.0 / 6\end{array}$ & $\begin{array}{l}\text { TGLA126 } \\
31.2 / 5\end{array}$ & $\begin{array}{l}\text { BM713 } \\
34.3 / 4\end{array}$ & $\begin{array}{l}\text { BM4107 } \\
52.4 / 4\end{array}$ & $\begin{array}{l}\text { BM5004 } \\
64.3 / 10\end{array}$ & & & \\
\hline 23 & $\begin{array}{l}\text { BM } 47 \\
0 / 5\end{array}$ & $\begin{array}{l}\text { BM1258 } \\
14.8 / 6\end{array}$ & $\begin{array}{l}\text { CYP21 } \\
26.9 / 9\end{array}$ & $\begin{array}{l}\text { BM1818 } \\
41.8 / 6\end{array}$ & $\begin{array}{l}\text { BM1905 } \\
55.2 / 6\end{array}$ & & & & \\
\hline 26 & $\begin{array}{l}\text { HEL11 } \\
0 / 10\end{array}$ & $\begin{array}{l}\text { BM4505 } \\
19.0 / 11\end{array}$ & $\begin{array}{l}\text { BM188 } \\
19.7 / 8\end{array}$ & $\begin{array}{l}\text { BM804 } \\
38.9 / 6\end{array}$ & & & & & \\
\hline
\end{tabular}

${ }^{1}$ See Nadesalingam (2001) and Plante (2001).

study. The significant QTL and $P$-values are listed in Table 4 for either ML or the regression method. The LOD score profiles for both methods are presented in Figure $1 \mathrm{a}$ and $\mathrm{b}$.

Five significant QTL $(P<0.05)$ were detected by both regression and ML methods on chromosomes 1, 3, 6, and 20. On chromosome 1, both methods detected a significant QTL for protein yield located between markers BM4307 and INRA011. On chromosome 3, both methods detected a significant QTL affecting milk yield around the marker INRA003, and a significant QTL affecting protein percentage between markers FCGR2 and INRA023. On chromosome 6, both methods uncovered a significant QTL affecting milk yield around marker BM415. On chromosome 20, both methods detected a significant QTL affecting protein yield between markers BM1225 and TGLA126. Four of these signifi- cant detections were previously reported (reviewed by Mosig et al., 2001). They are the QTL affecting protein yield on chromosome 1 (Zhang et al., 1998), the QTL affecting milk yield (Zhang et al., 1998) and protein percentage (Heyen et al., 1999) on chromosome 3, and the QTL affecting milk yield on chromosome 6 (Zhang et al., 1998). Recently, Ron et al. (2001), in their interval mapping of Israeli Holsteins, reported a test statistic profile of milk yield on chromosome 6 that was similar to ours. The significant position for protein yield on chromosome 20, at $19 \mathrm{cM}$ between BM1225 and TGLA126, has not been reported in the literature.

Aside from the above 5 significant positions detected by both methods, 5 additional positions were found to be significant $(P<0.05)$ by the ML method, but not by the regression method. These are the positions affecting fat yield between markers RM095 and ILSTS004 and

Table 3. Parameter combinations of the nine simulated cases.

\begin{tabular}{lccccccccc}
\hline Simulated cases & 1 & 2 & 3 & 4 & 5 & 6 & 7 & 8 & 9 \\
\hline No. of sires & 5 & 10 & 15 & 10 & 10 & 10 & 10 & 10 & 10 \\
No. of sons per sire & 150 & 75 & 50 & 50 & 150 & 75 & 75 & 75 & 75 \\
QTL variance ratio & 0.1 & 0.1 & 0.1 & 0.1 & 0.1 & 0.05 & 0.15 & 0.1 & 0.1 \\
Interval size (cM) & 10 & 10 & 10 & 10 & 10 & 10 & 10 & 5 & 20 \\
\hline
\end{tabular}


Table 4. Estimated QTL positions (cM) by ML and regression model (Reg) with $P$-values (in parentheses) greater than 0.05 in either of the two methods.

\begin{tabular}{cllllll}
\hline Chr. & Method & Milk & Fat & Protein & Fat\% & Protein\% \\
\hline 1 & ML & & $27(0.011)$ & $46(0.008)$ & $15(0.014)$ & \\
& Reg & & $27(0.051)$ & $46(0.035)$ & $17(0.076)$ & \\
3 & ML & $39(0.019)$ & & & $34(0.046)$ & $19(0.007)$ \\
& Reg & $39(0.043)$ & & & $34(0.095)$ & $27(0.048)$ \\
6 & ML & $41(0.010)$ & & & & $14(0.021)$ \\
& Reg & $40(0.033)$ & & & & \\
20 & ML & $20(0.027)$ & & $19(0.013)$ & & \\
& Reg & $21(0.100)$ & & $19(0.036)$ & & \\
\hline
\end{tabular}

fat percentage between markers TGLA49 and RM095 on chromosome 1, fat percentage around marker INRA023 on chromosome 3 , protein percentage between BM143 and BM4528 (closer to BM143) on chromosome 6, and milk yield between markers BM1225 and TGLA126 on chromosome 20 . The position affecting milk yield on chromosome 20 is located in the same marker interval as the position affecting protein yield, suggesting a possible pleiotropic effect of a single QTL or a joint effect of two closely linked QTL. Of these 5 significant positions, the position affecting protein percent on chromosome 6 has also been reported in an overlapping interval between markers BM143 and TGLA37 (Zhang et al., 1998; Spelman et al., 1996; and Velmala et al., 1999; Ron et al., 2001). These studies consistently show the existence of QTL affecting protein percentage on chromosome 6 . The significant position affecting fat percentage around marker INRA023 on chromosome 3 in this study was detected by Heyen et al. (1999) to be around the marker TGLA263. The marker TGLA263 is closely linked with INRA023 according to IBRP97 map (www.ri.bbsrc.ac.uk/cgi-bin/mapviewer?species=bov). This suggests the existence of a QTL affecting fat percentage in the neighborhood of markers INRA023 and TGLA263. Other 3 significant positions have not been reported in the literature. On chromosome 26, the LOD score profile reaches its maximum at the last marker position for fat yield $(P=0.010$ for $\mathrm{ML}$ and $P=0.019$ for regression method). This significant position indicates that a QTL may be located outside of the tested chromosome fragment.

Residual standard deviations $\left(\hat{\sigma}_{e}\right)$ and substitution effects for the significant QTL in Table 4 are listed in Table 5. The estimates of residual variances are smaller for ML method than for the regression method. The estimated effects of the significant QTL by both methods are consistent, and the rankings of the sire effects estimated by both methods are the same for all chromosome-trait-sire combinations. However, some differences in the estimates between these 2 methods are apparent. The LOD score profiles of the ML method show very similar patterns to those of the regression method (Figure 1a and b). The peaks of the statistic profiles for both methods usually overlap or are very close to each other. However, statistic profiles of the two methods differ notably in some cases, especially at the positions with less evidence for QTL detection. For example, the corresponding peaks of statistic profiles for fat percentage on chromosomes 10 and 17 are 6 and $16 \mathrm{cM}$ apart from each other, respectively (Figure 2).

\section{Simulation}

The number of significant tests out of 100 replicates of each case (Table 6 ) shows that the 2 methods did not differ in cases 1, 2, 5, 7 and 8. Notably, these cases have favorable combinations of parameters for QTL mapping because they have a greater number of sons per sire, a higher QTL variance ratio and/or a smaller interval size. In the remaining cases $3,4,6$, and 9 , which are less favorable for QTL mapping, the ML method shows a larger number of significant tests than the regression method (Table 6). The dispersion of estimated QTL positions (Table 7) was smaller in the ML method than in the regression method in 6 of 9 cases simulated. The parameters used in the simulation have explicit effects on the results. Notably, the family size (number of sons per sire), given a total sample size, has a very large influence on the number of significance tests (Table 6) and precision of QTL positions (Table 7), as shown in the first 3 cases. The estimated dispersion of QTL positions was much smaller with 150 sons per sire (case 1) than with 75 or 50 sons per sire (cases 1 and 3). In general, the results of the simulation study are consistent with those of field data, showing that the ML method has a higher number of significant tests than the regression method. The differences in number of significant tests and estimated QTL positions between the 2 methods tend to be larger in scenarios with unfavorable situations for QTL detection. 
A
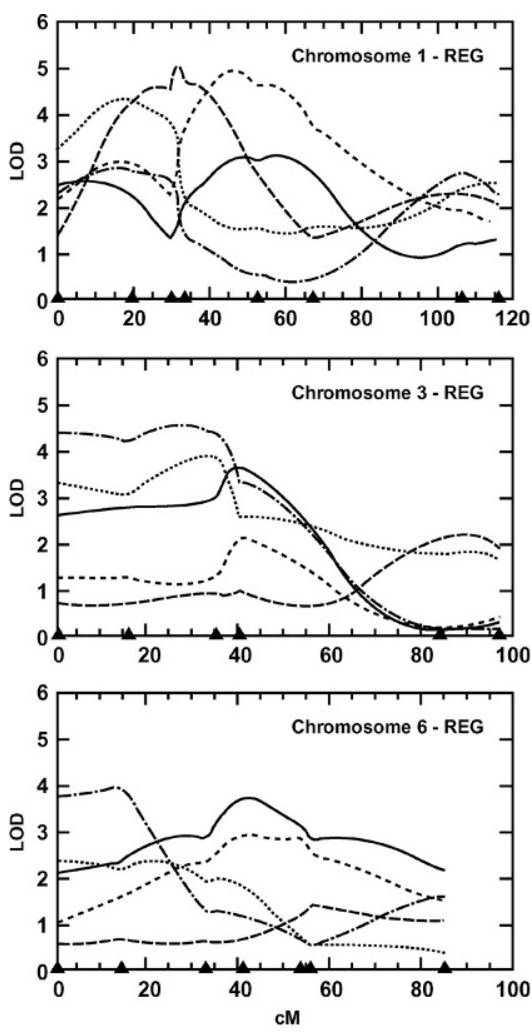

B

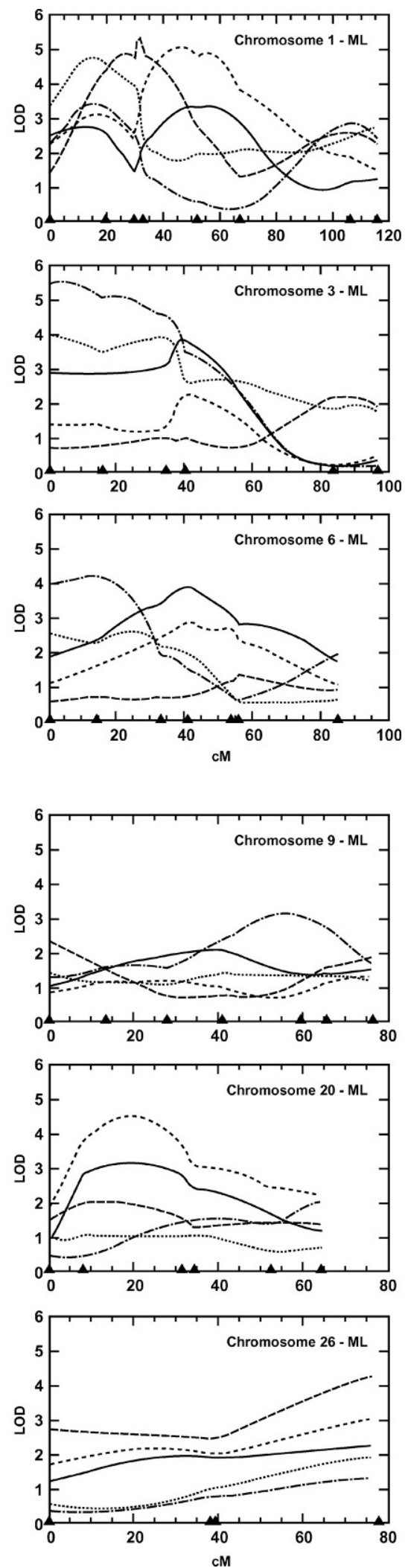

Figure 1. A. Profiles of LOD scores from the mixture model ML method and the regression method for chromosomes 1, 3 and 6. Legend: milk yield, - - - fat yield, ---- protein yield, . . - fat $\%,--_{-} \cdot-$ protein $\%$. B. Profiles of LOD scores from the mixture model ML method and the regression method for chromosomes 9,20 , and 26 . Legend: —— milk yield, - - - fat yield, ---- protein yield, $\cdots$ fat $\%,-\cdot-\cdot$ protein $\%$. 
Table 5. QTL effects and residual SD $\left(\hat{\sigma}_{e}\right)$ estimated by ML and regression method (Reg).

\begin{tabular}{|c|c|c|c|c|c|c|c|c|c|}
\hline \multirow[b]{2}{*}{ Chr. } & \multirow[b]{2}{*}{ Trait } & \multirow[b]{2}{*}{ Method } & \multirow[b]{2}{*}{$\hat{\sigma}_{e}$} & \multicolumn{6}{|c|}{ Sire } \\
\hline & & & & 1 & 2 & 3 & 4 & 5 & 6 \\
\hline & & ML & 13.09 & -8.74 & 6.21 & 2.15 & 13.84 & -1.49 & -5.34 \\
\hline 1 & Fat & Reg & 14.08 & -8.98 & 6.16 & 2.13 & 12.65 & -1.30 & -5.24 \\
\hline 1 & Protein & $\begin{array}{l}\text { ML } \\
\text { Reg }\end{array}$ & $\begin{array}{r}9.24 \\
10.07\end{array}$ & $\begin{array}{l}-9.19 \\
-9.08\end{array}$ & $\begin{array}{l}7.55 \\
8.15\end{array}$ & $\begin{array}{l}-0.84 \\
-0.76\end{array}$ & $\begin{array}{l}3.95 \\
4.63\end{array}$ & $\begin{array}{l}1.96 \\
1.95\end{array}$ & $\begin{array}{l}-8.23 \\
-6.35\end{array}$ \\
\hline 1 & Fat $\%$ & $\begin{array}{l}\text { ML } \\
\text { Reg }\end{array}$ & $\begin{array}{l}0.138 \\
0.151\end{array}$ & $\begin{array}{l}-0.029 \\
-0.028\end{array}$ & $\begin{array}{l}0.065 \\
0.053\end{array}$ & $\begin{array}{l}0.019 \\
0.023\end{array}$ & $\begin{array}{l}0.164 \\
0.175\end{array}$ & $\begin{array}{l}-0.080 \\
-0.082\end{array}$ & $\begin{array}{l}0.134 \\
0.078\end{array}$ \\
\hline 3 & Milk & $\begin{array}{l}\text { ML } \\
\text { Reg }\end{array}$ & $\begin{array}{l}343.0 \\
366.2\end{array}$ & $\begin{array}{l}-223.3 \\
-202.9\end{array}$ & $\begin{array}{l}-62.3 \\
-63.2\end{array}$ & $\begin{array}{l}200.8 \\
176.8\end{array}$ & $\begin{array}{l}151.1 \\
155.3\end{array}$ & $\begin{array}{l}6.4 \\
5.6\end{array}$ & $\begin{array}{l}-244.8 \\
-251.1\end{array}$ \\
\hline 3 & Fat $\%$ & $\begin{array}{l}\text { ML } \\
\text { Reg }\end{array}$ & $\begin{array}{l}0.142 \\
0.151\end{array}$ & $\begin{array}{l}0.131 \\
0.134\end{array}$ & $\begin{array}{l}-0.007 \\
-0.006\end{array}$ & $\begin{array}{l}-0.047 \\
-0.047\end{array}$ & $\begin{array}{l}-0.015 \\
-0.015\end{array}$ & $\begin{array}{l}-0.041 \\
-0.044\end{array}$ & $\begin{array}{l}0.079 \\
0.075\end{array}$ \\
\hline 3 & Protein $\%$ & $\begin{array}{l}\text { ML } \\
\text { Reg }\end{array}$ & $\begin{array}{l}0.053 \\
0.058\end{array}$ & $\begin{array}{l}0.047 \\
0.053\end{array}$ & $\begin{array}{l}0.011 \\
0.011\end{array}$ & $\begin{array}{l}-0.013 \\
-0.013\end{array}$ & $\begin{array}{l}-0.069 \\
-0.041\end{array}$ & $\begin{array}{l}-0.027 \\
-0.028\end{array}$ & $\begin{array}{l}0.022 \\
0.019\end{array}$ \\
\hline 6 & Milk & $\begin{array}{l}\text { ML } \\
\text { Reg }\end{array}$ & $\begin{array}{l}341.8 \\
363.9\end{array}$ & $\begin{array}{l}122.7 \\
134.1\end{array}$ & $\begin{array}{l}-171.6 \\
-168.1\end{array}$ & $\begin{array}{l}169.7 \\
158.2\end{array}$ & $\begin{array}{l}260.3 \\
280.6\end{array}$ & $\begin{array}{l}229.6 \\
226.0\end{array}$ & $\begin{array}{l}-43.5 \\
-41.2\end{array}$ \\
\hline 6 & Protein\% & $\begin{array}{l}\text { ML } \\
\text { Reg }\end{array}$ & $\begin{array}{l}0.055 \\
0.058\end{array}$ & $\begin{array}{l}-0.003 \\
-0.003\end{array}$ & $\begin{array}{l}-0.018 \\
-0.015\end{array}$ & $\begin{array}{l}-0.027 \\
-0.027\end{array}$ & $\begin{array}{l}-0.054 \\
-0.050\end{array}$ & $\begin{array}{l}-0.011 \\
-0.011\end{array}$ & $\begin{array}{l}0.020 \\
0.021\end{array}$ \\
\hline 20 & Milk & $\begin{array}{l}\text { ML } \\
\text { Reg }\end{array}$ & $\begin{array}{l}343.9 \\
367.2\end{array}$ & $\begin{array}{l}-235.9 \\
-273.9\end{array}$ & $\begin{array}{l}214.1 \\
208.9\end{array}$ & $\begin{array}{l}164.9 \\
146.4\end{array}$ & $\begin{array}{l}-169.1 \\
-181.4\end{array}$ & $\begin{array}{l}5.0 \\
6.6\end{array}$ & $\begin{array}{l}-161.8 \\
-156.4\end{array}$ \\
\hline 20 & Protein & $\begin{array}{l}\text { ML } \\
\text { Reg }\end{array}$ & $\begin{array}{r}9.35 \\
10.13\end{array}$ & $\begin{array}{l}-6.91 \\
-7.49\end{array}$ & $\begin{array}{l}8.54 \\
8.85\end{array}$ & $\begin{array}{l}7.00 \\
5.70\end{array}$ & $\begin{array}{l}-3.25 \\
-3.51\end{array}$ & $\begin{array}{l}1.04 \\
1.00\end{array}$ & $\begin{array}{l}-4.71 \\
-4.83\end{array}$ \\
\hline
\end{tabular}

\section{COMPARISON OF MAPPING METHODS}

During the last decade, many statistical methods for dairy cattle QTL mapping have been developed, such as regression method (Knott et al., 1996; Spielman et al., 1996), ML methods (Georges et al., 1995; Mackinnon and Weller, 1995; Knott et al., 1996; Song and Weller, 1998; Jansen et al., 1998), a residual ML method (Grignola et al., 1996a, 1996b) and Bayesian methods via Markov chain Monte Carlo (Uimari and Hoeschele, 1997; Bink et al., 2000). These methods differ in computational demands (Hoeschele et al., 1997), with regression being easiest, ML and REML intermediate, and Bayesian methods the most onerous.

Modeling QTL effects is a complicated issue because the allelic segregation at QTL is not observable and has to be inferred based on information about the linked markers. Unless a QTL is completely linked with a genetic marker, the inference is only up to the probabilistic distribution of QTL alleles or genotypes. There are different ways to model the uncertain QTL effects. 1) The mixture model for QTL mapping was proposed by Lander and Botstein (1989) for inbred populations and applied to half-sib designs of livestock in several
1

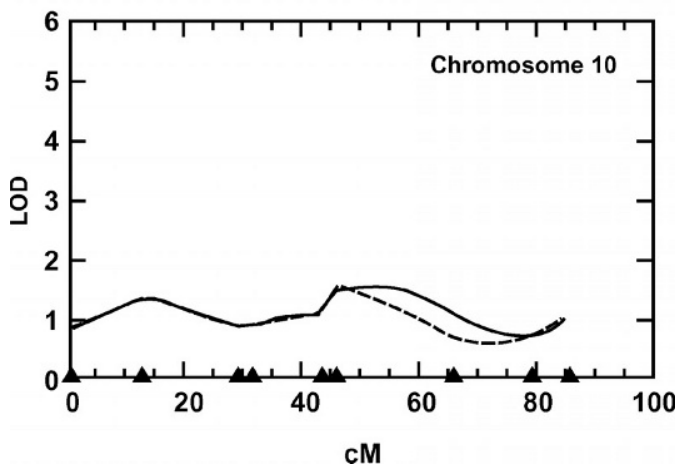

2



Figure 2. LOD score profiles for fat percent from the mixture model ML method and the regression method. Legend: - ML method, --- Regression method. 
LIU ET AL.

Table 6. Number of significant tests among 100 simulated replicates.

\begin{tabular}{lllllllllll}
\hline & & \multicolumn{8}{c}{ Simulated cases } \\
\cline { 3 - 10 } $\begin{array}{l}\text { Significance } \\
\text { level }(\alpha)\end{array}$ & Method & 1 & 2 & 3 & 4 & 5 & 6 & 7 & 8 & 9 \\
\hline 0.05 & ML & 93 & 83 & 76 & 64 & 95 & 43 & 95 & 88 & 74 \\
& Reg & 93 & 83 & 74 & 62 & 95 & 41 & 95 & 88 & 74 \\
0.01 & ML & 91 & 67 & 39 & 38 & 94 & 20 & 90 & 76 & 61 \\
& Reg & 91 & 67 & 36 & 39 & 94 & 21 & 90 & 76 & 59 \\
\hline
\end{tabular}

${ }^{1}$ Reg $=$ regression method.

studies (Mackinnon and Weller, 1995; Georges et al., 1995; Knott et al., 1996; Jansen et al., 1998). Johnson et al. (1999) also applied the model to selectively genotyped data. 2) The regression model was proposed by Haley and Knott (1992) and extended to QTL mapping of dairy cattle by Knott et al. (1996) and Spielman et al. (1996). In the model, the expectation of the uncertain QTL genotypes was taken as a covariate. 3) The gametic model was proposed originally by Fernando and Grossman (1989) for marker-assisted genetic evaluation and first applied to QTL mapping of livestock by Grignola et al. (1996). Of these models, the regression model and gametic model are conventional linear models.

The method presented in this study is a mixture model ML approach. The difference of this method from the previous ML methods (Mackinnon and Weller, 1995; Knott et al., 1996; Song and Weller, 1998) lies in the parameterization and likelihood structure. The previous studies assumed 2 alleles segregating at every putative QTL in the population and, therefore, the frequencies of the sire's QTL genotypes or population QTL allele frequencies were treated as parameters to be estimated. Prespecifying the number of alleles will reduce the practical applicability of these methods because the correct number of mixture components is crucial for correctly evaluating the mixture model for QTL mapping. Georges et al. (1995) treated the substitution effect of a sire's 2 alleles as parameters. This parameterization has the advantage that there is no need to specify the number of QTL alleles (Zhang et al., 1998) and, therefore, was extended in this study to deal with multiple sire families to increase the applicability. The stud- ies cited above included the distribution of sire's genotype in the likelihood function and, therefore, used rather complicated likelihoods. The mixture proportion is actually a joint probability of the sire's genotype and the progeny's QTL allele from the sire. Thus, the component likelihood for each paternal QTL allele and each progeny appears in the total likelihood repeatedly. This study treated the progeny's QTL paternal allele as the mixture factor. The probability of the alleles that progeny inherited from its sire was treated as mixture proportions. This leads to a succinct mixture likelihood function and makes derivation of the ML formulas easier. This study differs from Georges et al. (1995) mainly by using a simpler likelihood, joint analysis of families, and derived estimation formulas. This study differs from the method of Jansen et al. (1998) mainly in the likelihood structure. The likelihood of Jansen et al. (1998) was built on the joint distribution of observations. Clearly, the number of mixture components in the function is huge and increases exponentially with sample size. Jansen et al. (1998) worked on the sampling-based method. With that approach, it is difficult to do the exact likelihood analysis and employ the information of all mixture components. In contrast, the method of this study applies the mixture within each individual observation and makes exact likelihood analysis possible.

Theoretically, the mixture model ML method is expected to perform better in QTL mapping than the regression method. The ML method makes use of the posterior probability of the QTL allele conditional on marker information and observations, whereas the regression method uses the prior probability conditional

Table 7. Means and SD (in parentheses) of QTL positions (cM) estimated over 100 replicates.

\begin{tabular}{llcccccccc}
\hline & \multicolumn{8}{c}{ Simulated cases } \\
\cline { 2 - 9 } Method & 1 & 2 & 3 & 4 & 5 & 6 & 7 & 8 & 9 \\
\hline ML & 33.70 & 34.49 & 34.94 & 39.19 & 34.35 & 38.04 & 34.27 & 34.43 & 35.27 \\
& $(6.22)$ & $(11.13)$ & $(14.56)$ & $(20.69)$ & $(3.88)$ & $(21.89)$ & $(6.21)$ & $(11.51)$ & $(11.42)$ \\
\multirow{2}{*}{ Reg $^{1}$} & 33.21 & 33.03 & 35.19 & 39.39 & 33.48 & 38.05 & 33.36 & 33.36 & 35.37 \\
& $(6.72)$ & $(10.99)$ & $(15.21)$ & $(20.92)$ & $(3.85)$ & $(22.01)$ & $(6.56)$ & $(11.16)$ & $(12.78)$ \\
\hline
\end{tabular}

\footnotetext{
${ }^{1} \operatorname{Reg}=$ regression method.
} 
only on marker information. The use of phenotypic observations can result in a more accurate estimation of the probability of QTL genotypes or alleles transmitted. However, the comparison of the ML method and regression method can be complicated by other factors. For example, Kao (2000) found that the difference between the regression method and ML method depends on the similarity between the posterior probability $\left(\pi_{i j}\right)$ and the conditional probability $\left(p_{i j}\right)$ of QTL. The similarity between the two probabilities is in turn affected by QTL effects and positions in the marker interval and interval size. When the QTL to be tested is located in the middle of the marker interval, the two probabilities tend to differ the most, and the difference between the two methods tends to be the largest. The difference tends to be small when the QTL is close to or right at a marker.

Computationally, the ML analysis is an iterative process and generally requires more computing time than the regression method. However, considering the time and money invested on data collection and marker genotyping, even minor advantages in QTL detection would justify the extra time required for the ML analysis.

\section{CONCLUSIONS}

A ML method was developed and compared with the regression method for QTL mapping based on both field and simulation data. Both methods detected 5 significant positions, 4 of which are in agreement with previous studies. Additionally, 5 significant positions were detected by the ML method, but not by the regression approach. Two of these 5 positions have been reported in the literature. The ML method has a slightly higher statistical power, and yield more precise QTL locations, and a smaller residual variances than the regression method, especially in unfavorable situations for QTL detection. The simultaneous equations of the ML method were formulated as an analogue to conventional linear model equations to facilitate application and computer programming.

\section{ACKNOWLEDGMENTS}

We would like to thank Gordon Vander Voort for his assistance with data preparation and Yves Plante and John Gibson for providing the marker data. This study was supported by the Canadian Dairy Cattle Genetic Research and Development Council (DairyGen) and Agriculture and Agri-Food Canada (AAFC).

\section{REFERENCES}

Bink, M. C. A. M., L. L. G. Janss, and R. L. Quaas. 2000. Markov chain Monte Carlo for mapping quantitative trait locus in outbred populations. Genet. Res. Camb. 75:231-241.
Churchill, G. A., and R. W. Doerge. 1994. Empirical threshold values for quantitative trait mapping. Genetics 138:963-971.

Dempster, A. P., N. M. Laird, and D. B. Rubin. 1977. Maximum likelihood from incomplete data via the EM algorithm. J. R. Stat. Soc. 39:1-3.

Freyer, G., C. Kuhn, R. Weikard, Q. Zhang, M. Mayer, and I. Hoeschele. 2002. Multiple QTL on chromosome six in dairy cattle affecting yield and content traits. J. Anim. Breed. Genet. 119:69-82.

Georges, M., D. Nelson, M. Mackinnon, A. Mishra, R. Okimoto, A. T. Pasquino, L. S. Sargeant, A. Sorenson, M. R. Steele, X. Zhao, J. E. Womack, and I. Hoschele. 1995. Mapping quantitative trait loci controlling milk production in dairy cattle by exploiting progeny testing. Genetics 139:907-920.

Grignola, F. E., I. Hoeschele, and B. Tier. 1996a. Mapping quantitative loci in outcross populations via residual maximum likelihood. I. Methodology. Genet. Sel. Evol. 28:479-490.

Grignola, F. E., I. Hoeschele, Q. Zhang, and G. Thaller. 1996b. Mapping quantitative loci in outcross populations via residual maximum likelihood. I. A simulation study. Genet. Sel. Evol. 28:491-504.

Haley, C. S., and S. A. Knott. 1992. A simple regression method for mapping quantitative trait in line crosses using flanking markers. Heredity 69:315-324.

Heyen, D. W., J. I. Weller, M. Ron, M. Band, J. E. Beever, E. Feldmesser, Y. Da, G. R. Wiggans, P. M. Van Raden, and H. A. Lewin. 1999. A genome scan for QTL influencing milk production and health traits in dairy cattle. Physiol. Genomics 1:165-175.

Jansen, R. C., D. L. Johnson, and J. A. M. Van Arendonk. 1998. A mixture model approach to the mapping of quantitative trait loci in complex populations with an application to multiple cattle families. Genetics 148:391-399.

Johnson, D. L., R. C. Jansen, and J. A. M. Van Arendonk. 1999. Mapping quantitative trait loci in a selectively genotyped outbred population using a mixture model approach. Genet. Res. Camb. 73:75-83.

Kao, C. H. 2000. On the differences between maximum likelihood and regression interval mapping in the analysis of quantitative trait loci. Genetics 156:855-865.

Knott, S. A., J. M. Elsen, and C. S. Haley. 1996. Methods for multiplemarker mapping of quantitative trait loci in half-sib populations. Theor. Appl. Genet. 93:71-80.

Lander, E. S., and D. Botstein. 1989. Mapping Mendelian factors underlying quantitative traits using RFLP linkage maps. Genetics 121:185-199.

Little, R. J. A., and D. B. Rubin. 1987. Statistical Analysis with Missing Data. John Wiley \& Sons, New York, NY.

Liu, Y., and Z.-B. Zeng. 2000. A general mixture model approach for mapping quantitative trait loci from diverse cross designs involving multiple inbred lines. Genet. Res. 75:345-355.

Mackinnon, M. J., and J. I. Weller. 1995. Methodology and accuracy of estimation of quantitative trait loci parameters in a half-sib design using maximum likelihood. Genetics 141:755-770.

Meng, Xiao-Li, and D. B. Rubin. 1993. Maximum likelihood estimation via the ECM algorithm: A general framework. Biometrika 80:267-278.

Mosig, M. O., E. Lipkin, G. Khutoreskaya, E. Tchourzyna, M. Soller, and A. Friedmann. 2001. A whole genome scan for quantitative trait loci affecting milk protein percentage in Israeli-Holstein cattle, by means of selective milk DNA pooling in a daughter design, using an adjusted false discovery rate criterion. Genetics 157:1683-1698.

Nadesalingam, J., Y. Plante, and J. P. Gibson. 2001. Detection of QTL for milk production on chromosomes 1 and 6 of Holstein cattle. Mamm. Genome 12:27-31.

Plante, Y., J. P. Gibson, J. Nadesalingam, H. Mehrabanni-Yeganeh, S. Lefebvre, G. Vandervoort, and G. B. Jansen. 2001. Detection of quantitative trait loci affecting milk production traits on 10 chromosomes in Holstein cattle. J. Dairy Sci. 84:1516-1524.

Ron, M., D. Kliger, E. Feldmesser, E. Seroussi, E. Ezra, and J. I. Weller. 2001. Multiple quantitative trait locus analysis of bovine 
chromosome 6 in the Israeli Holstein population by a daughter design. Genetics 159:727-735.

Song, J. Z., and J. I. Weller. 1998. Maximum likelihood estimation of quantitative trait loci parameters with flanking markers in a half-sib population. Proc. 6th WCGALP 26:341-344.

Spelman, R. J., W. Coppieters, L. Karim, J. A. van Arendonk, and H. Bovenhuis. 1996. Quantitative trait loci analysis for five milk production traits on chromosome six in the Dutch HolsteinFriesian population. Genetics 144:1799-1808.

Uimari, P., and I. Hoeschele. 1997. Mapping-linked quantitative trait loci using Bayesian analysis and Markov chain Monte Carlo algorithm. Genetics 146:735-743.
Velmala, R. J., H. J. Vilkki, K. Elo, D. J. de Koning, and A. MakiTanila. 1999. A search for quantitative trait loci for milk production traits on chromosome 6 in Finnish Ayrshire cattle. Anim. Genet. 30:136-143.

$\mathrm{Xu}, \mathrm{S} .1995$. A comment on the simple regression method for interval mapping. Genetics 141:1657-1659.

Zeng, Z.-B. 1994. Precision mapping of quantitative trait loci. Genetics 136:1457-1468.

Zhang, Q., D. Boichard, I. Hoeschele, C. Ernst, A. Eggen, B. Murkve, M. Pfister-Genskow, L. A. Witte, F. E. Grignola, P. Uimari, G. Thaller, and M. D. Bishop. 1998. Mapping quantitative trait loci for milk production and health of dairy cattle in a large outbred pedigree. Genetics 149:1959-1973. 